\title{
Dermatological Manifestations In Human Immunodeficiency Virus Infected Patients: Histopathology and CD4 Cell Count Correlation
}

\author{
Poonam Radadiya and Sheetal Kher* \\ Dept of Pathology, GMERS Medical College, Gotri, Vadodara (India)
}

\begin{abstract}
Background: More than $90 \%$ of the Human immunodeficiency virus (HIV) infected patients develop skin lesions at some point throughout the course of the disease. Although these conditions may be seen in general healthy population, their occurrence in patients with acquired immunodeficiency syndrome is often atypical, more severe and explosive. Histopathology study of skin biopsies from these lesions is very useful for the final diagnosis of these lesions.
\end{abstract}

Methods: Total 60cases were studied. Punch biopsies from the skin lesions were studied with routine histopathology examination and special stains were used as and when required. The results were divided into infectious and non-infectious categories. Results were correlated with the CD4 counts of the patients.

Results: Out of that22 (36.66\%) patients had infectious lesions and $38(63.33 \%)$ patients had non-infectious lesions. The spectrum of various non-infectious and infectious lesions such as viral, bacterial, fungal, protozoa, dermatitis, popular lesions and their association with CD4 counts is discussed.

Conclusion: In present study mean CD4 cell count was found to be low $(<350)$ in individuals with infectious skin lesions, where as noninfectious lesions were associated with higher $(>350)$ CD4 cell counts.

Keywords: CD4, Histopathology, Human Immunodeficiency Virus, Punch Biopsy, Skin Lesions

\section{Introduction}

India has the third largest HIV epidemic in the world. In 2015, HIV prevalence in India was estimated $0.26 \%$. ${ }^{[1]}$ Diseases of skin and mucous membranes are common clinical manifestations of acquired immunodeficiency syndrome (AIDS). Cutaneous disorders may be the initial signs of HIV-related immunosuppression. Cutaneous disorders are not only associated with terminal immunodeficiency, but also occur throughout the course of human immunodeficiency virus (HIV) infection. Cutaneous manifestations of human immunodeficiency virus (HIV) may result from HIV infection itself or from opportunistic disorders secondary to decline in immunocompetence from the disease. ${ }^{[2]}$ More than $90 \%$ of patients develop skin lesions at some time during the disease. In some patients, skin is the first organ affected. ${ }^{[3]}$ Skin diseases have proved to be sensitive and useful measures by which HIV progression can be monitored. Impaired skin immune system occurring early in HIV disease is believed to be responsible for the frequent occurrence of both infectious and non-infectious skin diseases even before the development of full blown HIV infection. ${ }^{[4]}$ Although skin lesions may be seen in the general healthy population, their occurrence in HIV infected patients is often atypical and more severe, explosive, extensive or resistant to therapy. The unusual histology of some of the diseases in AIDS may contribute to misdiagnosis. Thus, proper histological diagnosis of skin manifestations is very important as it may serve as the earliest manifestation to suspect a case of HIV infection. Infectious agents can produce skin lesions even though the classic organ of involvement for that agent does not include the skin.

\section{Materials and Methods}

This was a prospective observational study of 1 year duration carried out in the Department of Pathology of a tertiary referral center. Total 60 known HIV positive patients of all ages with symptomatic skin lesions attending skin and venereal disease out-patient department and Anti Retroviral Therapy Clinic at this center were included in the study. Patient's HIV positivity was confirmed by three different sets of Ag systems (HIV comb-AIDS Rapid test, Rapid spot test and Tridot). The complete clinical details, in particular skin lesions were noted along with CD4 counts. Irrespective of any other systemic involvement or presence of other STDs, only skin lesions were sampled after taking informed written consent. The lesions were sampled using 
the punch biopsy and the diagnosis was made with routine histopathology examination and with the help of special stains as and when required. Pertinent clinical history like age, duration of the lesion, site of the lesion, significant family and personal history, history of associated diseases and any drug intake was taken and entered in the Performa. After detailed general and local examination, the site of the biopsy was selected. All universal aseptic precautions according to National AIDS Control Organization guidelines were followed. The selected patient's consent was taken after explaining the details of the biopsy procedure. The three dimensional size and shape of the skin biopsy was assessed including the circular or elliptical shape of the biopsy for gross examination. The biopsy obtained was processed by standard formalin fixing paraffin embedding method. Serial sections and special stains were studied as and when required. The diagnosis was correlated with the CD4 counts.

\section{Results}

Out of total 60 known HIV infected patients, 43 were males and 17 were female patients. Maximum numbers of cases were seen in between 31 and 40 years of age group [Table 1]. CD4 counts were correlated in all 60 cases. Out of $60 \mathrm{HIV}$ infected patients, 18 (30\%) patients had CD4 counts $<350,33$ patients showed CD4 counts between 350 to500, 09 patients had CD4 count $>500$. Out of this
60 cases, $22(36.66 \%)$ had infectious pathology, whereas $38(63.33 \%)$ patients had non-infectious pathology. Variety of infectious skin lesions were observed such as viral, bacterial, fungal and parasitic (Arthropod) infections. Total $07(11.6 \%)$ patients showing viral pathology included Molluscum contagiosum, human papilloma virus (HPV), herpes zoster and herpes simplex virus (HSV). Total 08 $(13.3 \%)$ patients had bacterial infections, which included leprosy, cutaneous tuberculosis, folliculitis, syphillis, donovanosis and furunculosis. One $(1.6 \%)$ case of parasitic infections was seen which was of leishmaniasis. Total fungal infections were $06(10 \%)$, which included candidiasis, dermatophytoses-tinea, cryptococcosis and histoplasmosis. Infectious results were correlated with the CD4count of the patients [Table 2]. Which shows most (15 out of 22) of the patients with infectious lesions had CD4count less than 350 . Out of 38 non-infectious patients, majority of patients (10) had papular lesions including pruritic papular eruptions (PPE), seborrheic dermatitis, psoriasis, eosinophilic folliculitis and lichen planus. Total four patients had vascular lesion and three patients had malignant/premalignant lesions, whereas two patients had other non-specific pathology including follicular keratosis and perforating keratosis. These results were correlated with CD4counts of the patients [Table 3]. Which shows most of the patients (35 out of 38 ) with non-infectious lesions had CD4count more than 350 .

Table 1: Age distribution in the present study.

\begin{tabular}{|c|c|c|c|}
\hline Sr.no. & Age in years & Number & \% \\
\hline 1. & $21-30$ & 20 & 33.3 \\
\hline 2 & $31-40$ & 25 & 41.6 \\
\hline 3 & $41-50$ & 11 & 18.3 \\
\hline 4 & $51-60$ & 4 & 6.6 \\
\hline
\end{tabular}

Table 2: Infectious lesions observed in the study with CD4 count correlation.

\begin{tabular}{|c|c|c|c|c|c|c|c|}
\hline Sr no & Histopathological diagnosis & Numb er $(n=60)$ & $\%$ & Mean CD4 & CD4 Count & & \\
\hline & & & & & $<350$ & $350-500$ & $>500$ \\
\hline 1 & $\begin{array}{l}\text { Viral lesions:- Warts, Condyloma } \\
\text { Lata, Molluscum contagiosum }\end{array}$ & 07 & 11.6 & 343.28 & 5 & 1 & 1 \\
\hline 2 & $\begin{array}{l}\text { Bacterial infections:- Chanchroid, } \\
\text { Hansens, Tuberculosis verrucosa } \\
\text { cutis, Folliculitis, Pustular } \\
\text { lesion, Lupus vulgaris, Syphilis, } \\
\text { Pyoderma gangrenosum. }\end{array}$ & 08 & 13.3 & 394.5 & 3 & 2 & 3 \\
\hline 3 & $\begin{array}{l}\text { Fungal infections:- Candidiasis, } \\
\text { Cryptococcus, Histoplasma, } \\
\text { TineaCorporis }\end{array}$ & 06 & 10 & 144.66 & 6 & 0 & 0 \\
\hline \multirow[t]{2}{*}{4} & $\begin{array}{l}\text { Parasitic \&Protozoal infections:- } \\
\text { Leishmaniasis, Scabies }\end{array}$ & 01 & 1.6 & 256.0 & 1 & 0 & 0 \\
\hline & Total & 22 & 36.66 & & 15 & 3 & 4 \\
\hline
\end{tabular}


Table 3: Non infectious lesions observed in this study with CD4 count correlation.

\begin{tabular}{|c|c|c|c|c|c|c|c|}
\hline \multirow{2}{*}{$\begin{array}{c}\text { Sr } \\
\text { no. }\end{array}$} & \multirow[b]{2}{*}{ Histopathological diagnosis } & \multirow{2}{*}{$\begin{array}{l}\text { Numb er } \\
(n=60)\end{array}$} & \multirow[b]{2}{*}{$\%$} & \multirow{2}{*}{$\begin{array}{l}\text { Mean } \\
\text { CD4 }\end{array}$} & \multicolumn{3}{|c|}{ CD4 Count } \\
\hline & & & & & $<350$ & $350-500$ & $>500$ \\
\hline 1. & $\begin{array}{l}\text { Dermatitis:- Atopic Dermatitis, Ashy } \\
\text { Dermatitis, Urticaria, Hyperpigmented patch, } \\
\text { chronic non-specific dermatitis. }\end{array}$ & 08 & 13.3 & 421.62 & 1 & 6 & 1 \\
\hline 2. & $\begin{array}{l}\text { Papular lesion:- Pruritic papular, Psoriasis, } \\
\text { Seborrhoic Dermatitis, Eosinophilic folliculitis, } \\
\text { Scaly lesion, Lichen planus }\end{array}$ & 10 & 16.6 & 428.7 & 0 & 9 & 1 \\
\hline 3 & $\begin{array}{l}\text { Epidermal Lesion:- Epidermoid cyst, } \\
\text { Seborrhoic keratosis }\end{array}$ & 03 & 5.0 & 438.0 & 0 & 3 & 0 \\
\hline 4 & Drug reaction & - & - & & \multicolumn{3}{|c|}{-} \\
\hline 5 & $\begin{array}{l}\text { Vascular lesion:- Leukocytoclastic vasculitis, } \\
\text { Granuloma Pyogenicum }\end{array}$ & 04 & 6.6 & 427.25 & 0 & 3 & 1 \\
\hline 6 & $\begin{array}{l}\text { Connective tissue lesion:- DLE, Granuloma } \\
\text { Annulare }\end{array}$ & 04 & 6.6 & 422.75 & 0 & 3 & 1 \\
\hline 7 & $\begin{array}{l}\text { Malignant/Premalignant lesion:- Verrucous } \\
\text { Carcinoma, Squamous cell carcinoma, } \\
\text { Bowenoid papulosis }\end{array}$ & 03 & 5.0 & 273.66 & 2 & 1 & 0 \\
\hline 8 & $\begin{array}{l}\text { Vesiculobullous lesion:- Pemphigus vulgaris, } \\
\text { Bullous pemphigoid, Bullous impetigo, } \\
\text { Erythema Multiforme }\end{array}$ & 04 & 6.6 & 448.25 & 0 & 4 & 0 \\
\hline 9 & $\begin{array}{l}\text { Others:- Follicular keratosis, Perforating } \\
\text { folliculitis }\end{array}$ & 02 & 3.3 & 475.0 & 0 & 1 & 1 \\
\hline & Total & 38 & 63.33 & 377.01 & 3 & 30 & 5 \\
\hline
\end{tabular}

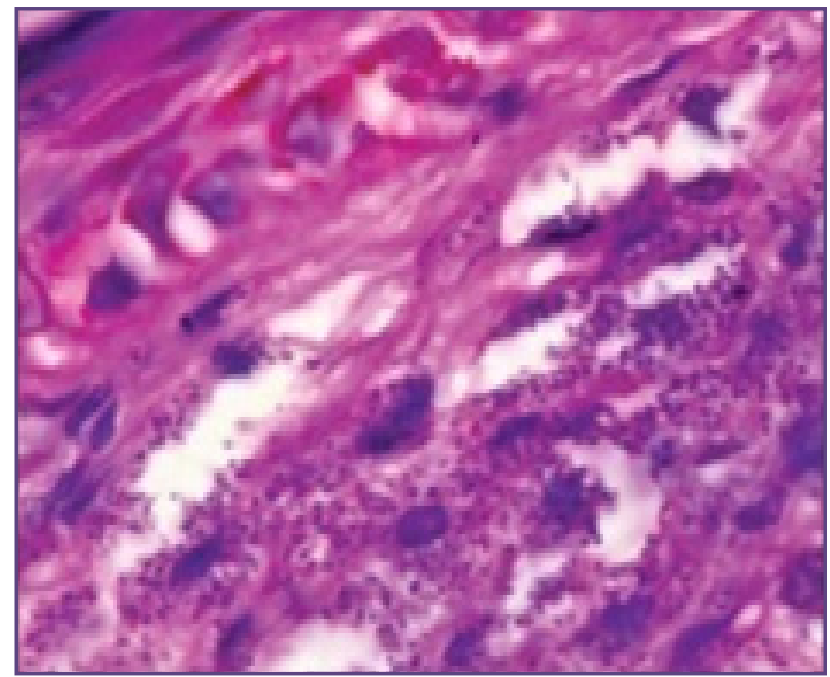

Fig. 1: Photograph showing cutaneous leishmaniasis: LD bodies are seen intracellularly in macrophages and extracellularly [H\&E stain, 100x].

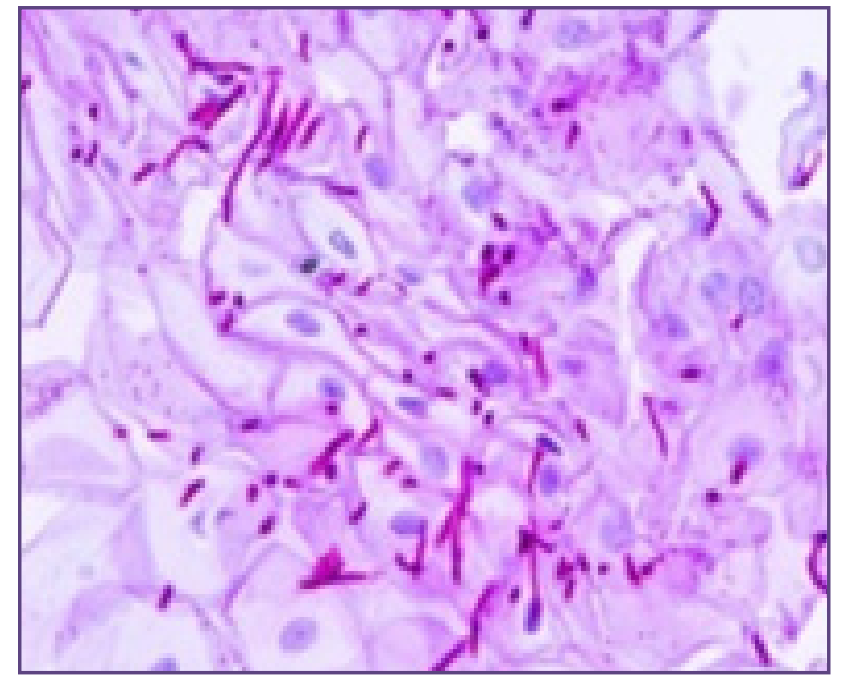

Fig. 2: Cutaneous candidiasis showing budding hyphae (red stained) [PAS stain, 100x]. 


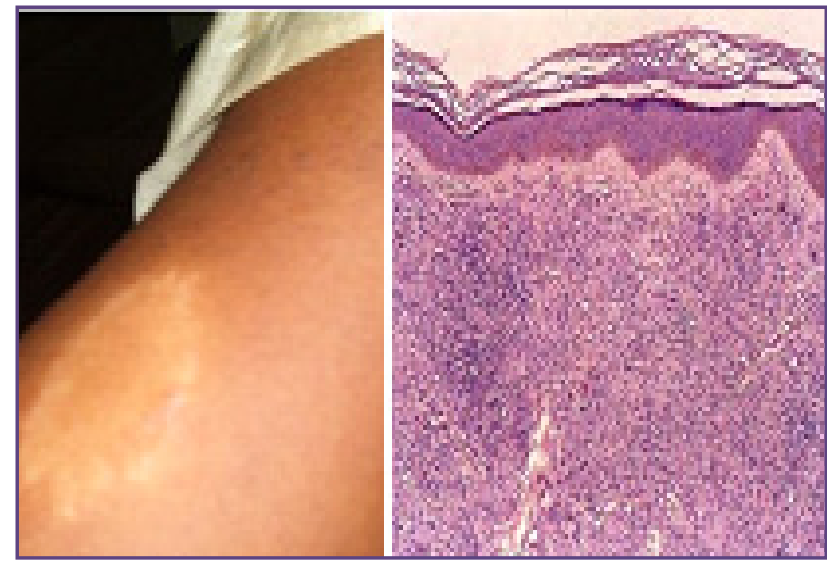

Fig. 3: Leprosy: Hypopigmented patch over forearm and microscopic picture showing atrophic epidermis with compact granuloma along neurovascular bundle [H\&E stain, 10x].

\section{Discussion}

Although a lot of literature regarding the etiology of cutaneous manifestations in HIV patients is available in Western world and some parts of Asia, very few case studies in Indian patients are available. In the present study the most affected age group was $21-40$ years constituting $74.9 \%$ and a second peak in the age $>40$ years with $24.9 \%$. In the study conducted by Sanjay M. Chawhan et al. most of the patients were from 31 to 40 years age group ${ }^{[5]} \mathrm{In}$ the study conducted by Nirja jindal ${ }^{[6]}$ most affected age group was $21-40$ years constituting $73.7 \%$ and a second peak in the age group $>40$ years with $21 \%$. A study by Kumarasamy et al. had 50\% patients between 18 and 30 years age group ${ }^{[7]}$ In the present study, we found $71.6 \%$ male patients as compared with $28.3 \%$ females, with 2.5 : 1 , male to female ratio. The study conducted by Sanjay M. Chawhan et al. showed $67 \%$ male patients as compared with $33 \%$ females. ${ }^{[5]}$ A study done by Nirja jindal showed female preponderance with a male to female ratio of 0.9:1. [6] This difference may be due to difference in geographical distribution. In our study of $60 \mathrm{HIV}$ infected patients, CD4 correlation was done in all patients. Maximum patients, i.e., 33 (55\%) had CD4 count between 350 to 500, followed by $18(30 \%)$ patients with CD4 counts below350and $09(15 \%)$ patients had CD4 counts above 500. Maximum number of infective lesions and malignancy were seen in patients with CD4 counts below 350 [Table 2].Whereas patients with CD4 count above 350 showed minimum infective, but more of the non-infectious lesions [Table 3]. Which is similar to the results of the study done by Sanjay M. Chawhan et al. which show Maximum number of infective lesions in patients with CD4 counts below 350 whereas patients with CD4 count above 350 showed minimum infective, but most of the non-infectious lesions. ${ }^{[5]}$ Previous

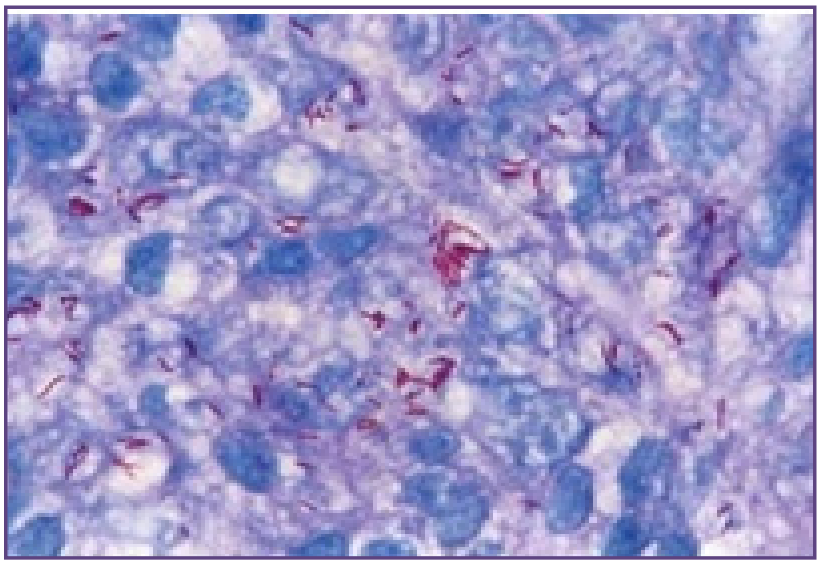

Fig. 4: Lepromatous Leprosy: Rod shaped Lepra bacilli stained pink in blue background [Fite-Faraco stain, 100x].

studies showed that CD4 counts $<200$ cells/cumm were associated with more number of infectious lesions. ${ }^{[4,8,9,10,11]}$ Muñoz-Pérez (1998) stated that various dermatoses such as genital herpes, tinea, Kaposi's sarcoma, xerosis, HSV, drug eruptions, candidial folliculitis, M. contagiosum, psoriasis, abscess, verruca vulgaris, PPE, oral hairy leukoplakia and seborrheic dermatitis could be used as clinical markers of disease progression due to their strong association with CD4 counts. ${ }^{[12]}$. We found that 22 out of 60 (36.66\%) patients had infectious lesions. Unusual clinical presentations of common skin infections or florid, unusual forms had been described in these patients by various authors. ${ }^{\left[{ }^{[3]}\right.}$ In these patients, infectious agents can produce skin lesions even though the classic organs of involvement for that agent do not include the skin, e.g., cryptococcosis, Cytomegalovirus and histoplasmosis. We found $07(11.6 \%)$ patients with viral lesions, $08(13.3 \%)$ patients with bacterial lesions including leprosy, $06(10 \%)$ patients with fungal infection and $01(1.6 \%)$ patient with parasitic lesion containing leishmaniasis [Figure1]. In the study by Sanjay M. Chawhan maximum infectious lesions were of viral etiology ${ }^{[5]}$ Maximum patients showed CD4 counts $<350$ as studied by other authors. The HPV related lesions were verruca vulgaris, verruca plana and bowenoid papulosis and condylomata accuminata. Muñoz-Pérez et al. found no significant difference between the incidence of condyloma acuminata or verruca vulgaris in stage III and stage IV disease or with CD4 counts. ${ }^{[12]}$ Muñoz-Pérez et al. in their study mentioned that HIV infection itself predisposes to an increased risk of HPV infection that is not directly related to the degree of immunosuppression. ${ }^{[12]}$ Nichols et al. stated that bacterial infections in AIDS were often under represented. ${ }^{[13]}$ In our study we found $08(13.3 \%)$ cases of bacterial infection including Mycobacterium infections as 
compared to $14(12.72 \%)$ cases of bacterial infection in the study by Sanjay M Chawhan et al. ${ }^{[5]}$ Dermatological lesions of tuberculosis (TB) infection are rarely found in Western countries. ${ }^{[14]}$ Various mycobacterium lesions in our study were leprosy (three cases of borderline tuberculoid and one case of tuberculoid leprosy), papulonecrotic tuberculid, scrofuloderma and TB cutis orificialis one each. In this study, six cases of fungal lesions were found which includes cases of dermatophytoses and candidiasis, histoplasmosis and cryptococcosis. All the patients with Fungal infections had CD4 counts below 350 cells/cumm. Which is similar to the study by Sanjay M Chawhan et al. ${ }^{[5]}$ We found $1(1.6 \%)$ case of parasitic infection, which is of dermal leishmaniasis. Sanjay M Chawhan et al. reported $7(6.36 \%)$ cases of parasitic infection, which included six cases of demodicidosis and one case of scabies. ${ }^{[5]}$ Kaplan et al. reported four cases of scabies who presented with pruritic dermatitis. Clinically, the lesions of scabies may resemble psoriasis vulgaris or Darier's disease. ${ }^{[9,15]}$ The most common non-infectious skin manifestation found in our study was PPE. The study by Sanjay M Chawhan et al. showed similar results. ${ }^{[5]}$ They were intensely pruritic, papular lesions more on the trunk and extremities with a predominance of eosinophils as described by Francis. The severe form of similar eruptions is seen in African and Haitian patients. ${ }^{[8]}$ Hevia et al. (1991) mentioned histological and clinical criteria for the diagnosis of these lesions. ${ }^{[16]}$ Most of the cases of PPE in our study were seen with CD4 counts more than 350 cells/cumm. We have found three cases of eosinophilic folliculitis. Rosenthal et al. found its association in patients with CD4 counts between 200 and 500 cells/cumm. ${ }^{[17]}$ It could be an important clinical marker of HIV infection, particularly in patients at increased risk of developing opportunistic infection. The clinical and histological differential diagnoses of eosinophilic folliculitis include demodicidosis and PPE. We found three cases of psoriasis. Incidence of psoriasis as high as $70 \%$ had been reported by Duvic et al. ${ }^{[18]} \mathrm{We}$ found one case of seborrheic keratosis. Although, it is mentioned that the incidence of seborrheic dermatitis is very high from $40 \%$ to $83 \%$ in Western literature; and in some other studies. ${ }^{[19]}$ Two cases of granuloma pyogenicum are noted and four cases of connective tissue lesions are identified. In Malignant and premalignant conditions, three cases were reported; verrucous carcinoma, squamous cell carcinoma and bowenoid papulosis, one of each. Miscellaneous group included 2 cases of perforating folliculitis and follicular keratosis. Total eight cases of dermatitis were reported. In this study, no any case of Kaposi's sarcoma or lymphoma were found. Wiwanitkit (2004), D. N. Lanjewar (2011) and Sanjay M Chwhan (2013) also found striking low prevalence of cutaneous and other malignancies in these patients. ${ }^{[10,20,5]}$ No any cases related to drug reactions are reported. Histological variations from normal were noted in certain lesions. In many biopsies, Periadnexal and perivascular inflammatory infiltrate, i.e., lymphocytic infiltration was seen in most of the lesions irrespective of histological diagnosis. Epidermal hyperplasia in the form of acanthosis, irregular parakeratosis or hyperkeratosis was seen in most of the lesions. None of the lesions showed normal epidermis. To summarize, in the present study on skin lesions in HIV infected individuals, infectious skin lesions were seen more commonly with CD4 counts below 350 and non-infectious skin lesions were seen more commonly with CD4 counts more than 350 . The most common infectious lesion was because of viral infections followed by bacterial infections and most common noninfectious lesion was PPE. Strikingly low occurrence of cutaneous malignancies was seen in the present study.

\section{Abbreviations}

HIV- Human immunodeficiency virus

PPE- Pruritic papular eruption

HSV- Herpes simplex virus

HPV- Human papilloma virus

\section{References}

1. NACO (2015) 'Annual report 2015-16'.www.naco.gov.in

2. Cedeno-Laurent F, Gomez-Flores M, Mendez N, AncerRodriguez J, Bryant JL, Gaspari AA, et al. New insights into HIV-1-primary skin disorders. J int AIDS soc.,2011 jan 24. 14:5.

3. Coldiron BM, Bergstresser PR. Prevalence and clinical spectrum of skin disease in patients infected with human immunodeficiency virus. Arch Dermatol. 1989;125:357-61.

4. Tschachler E, Bergstresser PR, Stingl G. HIV-related skin diseases. Lancet. 1996;348:659-63.

5. Chawhan SM, Bhat DM, Solanke SM. Dermatological manifestations in human immunodeficiency virus infected patients: Morphological spectrum with CD4 correlation. Indian J Sex Transm Dis. 2013 Jul-Dec; 34(2): 89-94.

6. Jindal N, Aggarawal A. HIV seropositive and HIV associated dermatosis among patients presenting with skin and mucocutaneous disorders. Indian journal of dermatology, venerology andleprology. 2009;75:283-286.

7. Kumarasamy N, Vallabhaneni S, Flanigan TP, Mayer KH, Solomon S. Clinical profile of HIV in India. Indian J Med Res. 2005;121:377-94.

8. Francis N. Non-neoplastic, cutaneous and mucocutaneous manifestations of HIV infection. Histopathology. 1993;23:297-305.

9. Kaplan MH, Sadick N, McNutt NS, Meltzer M, Sarngadharan MG, Pahwa S. Dermatologic findings and manifestations of 
acquired immunodeficiency syndrome (AIDS) J Am Acad Dermatol. 1987;16:485-506.

10. Wiwanitkit V. Prevalence of dermatological disorders in Thai HIV-infected patients correlated with different CD4 lymphocyte count statuses: A note on 120 cases. Int J Dermatol. 2004;43:265-8.

11. Kumarasamy N, Solomon S, Madhivanan P, Ravikumar B, Thyagarajan SP, Yesudian P. Dermatologic manifestations among human immunodeficiency virus patients in south India. Int J Dermatol. 2000;39:192-5.

12. Muñoz-Pérez MA, Rodriguez-Pichardo A, Camacho F, Colmenero MA. Dermatological findings correlated with CD4 lymphocyte counts in a prospective 3 year study of 1161 patients with human immunodeficiency virus disease predominantly acquired through intravenous drug abuse. $\mathrm{Br}$ J Dermatol. 1998;139:33-9.

13. Nichols L, Balogh K, Silverman M. Bacterial infections in the acquired immune deficiency syndrome. Clinicopathologic correlations in a series of autopsy cases. Am J Clin Pathol. 1989;92:787-90.

14. Dover JS, Johnson RA. Cutaneous manifestations of human immunodeficiency virus infection. Part II. Arch Dermatol. 1991;127:1549-58.
15. Inserra DW, Bickley LK. Crusted scabies in acquired immunodeficiency syndrome. Int J Dermatol. 1990;29:287-9.

16. Hevia O, Jimenez-Acosta F, Ceballos PI, Gould EW, Penneys NS. Pruritic papular eruption of the acquired immunodeficiency syndrome: A clinicopathologic study. J Am Acad Dermatol. 1991;24:231-5.

17. Rosenthal D, LeBoit PE, Klumpp L, Berger TG. Human immunodeficiency virus-associated eosinophilic folliculitis. A unique dermatosis associated with advanced human immunodeficiency virus infection. Arch Dermatol. 1991;127:206-9.

18. Duvic M, Johnson TM, Rapini RP, Freese T, Brewton G, Rios A. Acquired immunodeficiency syndromeassociated psoriasis and Reiter's syndrome. Arch Dermatol. 1987;123:1622-32.

19. Vasudevan B, Sagar A, Bahal A, Brig AP, Mohanty VS. Cutaneous manifestations of HIV - A detailed study of morphological variants, markers of advanced disease, and the changing spectrum. Med $\mathrm{J}$ Armed Forces India. 2012;68:20-7.

20. Lanjewar DN. The spectrum of clinical and pathological manifestations of AIDS in a consecutive series of 236 autopsied cases in mumbai, India. Patholog Res Int 2011. 2011547618.

*Corresponding author:

DR SHEETAL KHER, Dept of Pathology GMERS Medical college, Gotri, Vadodara (India)-390021

Phone: 02652398008

Email: drsheetalkher@gmail.com

Date of Submission : 04.06.2017

Date of Acceptance : 11.09.2017

Financial or other Competing Interests: None.
Date of Publication : 22.12.2017 